\title{
Optimization and Application of Support Scheme for Tunnel with High In-situ Stress in Ningchan
}

\author{
ZHANG Xueqiang ${ }^{1 *}$ \\ ${ }^{1}$ Qinghai Communications Construction Management Co, Ltd., Xining, Qinghai, 810003, China
}

\begin{abstract}
Based on the national highway 569 Mandala Datong highway Ningchan tunnel, the study on the optimization design of high ground stress tunnel support parameters is carried out. The results show that the single-layer primary support with I20b as the main support framework cannot control the large deformation of high ground stress tunnel, mainly manifested as arch frame failure and concrete spalling; adopting "double-layer initial support" can control large deformation to a certain extent; increasing the stiffness of inner layer support can reduce the "double-layer" to a certain extent The results show that the cumulative deformation of "support", but cannot significantly shorten the deformation stability period; appropriately increasing the reserved deformation between the inner and outer layers of the initial support has the best supporting effect, the cumulative deformation is small, and the deformation stability period is shortened. The research results provide a basis for similar high stress tunnel support measures.
\end{abstract}

\section{Introduction}

The stability of tunnel rock masses is controlled by various structural planes formed by the ground stress on the site and the interaction between ground stress field and rock masses. Ground stress is not only an important factor that determines the regional stability, but also a fundamental force for deformation and failure of underground engineering. It is a prerequisite for determining the properties of engineering rock mass mechanics, analyzing the stability of surrounding rock and realizing scientific excavation design and decisionmaking of geotechnical engineering [1,2]. Due to the poor self-stability of surrounding rocks, tunnel construction in high ground stress areas is prone to serious engineering problems such as rock burst, large deformation, intrusion, collapse or lining damage [3], which will not only worsen the engineering geological conditions of tunnel rock masses, but also cause direct harms to structures. Therefore, the selection of reasonable support measures has become a challenge in engineering construction.

Up to now, scholars at home and abroad have done a lot of research work on the support measures of tunnels with high ground stress [4-6]. Wang Daoyuan et al. [7-8] carried out field test researches on the control method of large deformation of high ground stress tunnel, and summed up the support concept of "flexible support before rigid support, deformation before stabilization, and combination of both". Wang Bo et al. [9] think that "yielding support" is more suitable for tunnels with high ground stress than "strong support" and "layered support". On the other hand, Cui Guangyao et al. [10] conducted the field test at Zhongyi Tunnel, and believe that the effect of "strong support" was better. In China, Wushaoling Tunnel on Lanzhou-Xinjiang Railway [11] and Muzhailing Tunnel on Lanzhou-Chongqing Railway [12-14] have successfully passed through the high ground stress areas by means of "multi-layer support" and "pilot tunnel stress release". Zheng Xixi et al., after analyzing the surface deformation law and influencing factors caused by tunnel construction, put forward targeted design schemes and control measures based on project features [15].

However, up to now, no support measure suitable for tunnels with high ground stress is clearly given in either relevant codes or practice summary. Disasters caused by high ground stress during tunnel construction process are still common, so it is necessary to further summarize and refine the effective support measures to enrich the sample database.

In this paper, relying on Ningchan high ground stress tunnel, the experimental study of support parameters is carried out on the basis of high ground stress tests. By means of field test and theoretical analysis, the support effects of different support methods are monitored and measured by optimizing support parameters, and reasonable support parameters for expressway tunnels crossing high ground stress areas are put forward to provide successful cases for similar projects..

\section{Project overview}

Ningchan Tunnel is located in Xianmi Township, Menyuan County in the section from Ningchan Pass to Ketu on National Highway 569 Mandela-Datong Highway. It is a two-way twin-bore four-lane tunnel of Class I highway. The starting/ending mileage peg

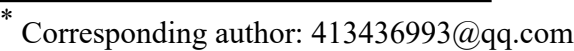


numbers of the left and right tunnels are ZK37+140 ZK43+164 and YK37+190 YK43+133 respectively, and the excavation area is $114 \mathrm{~m} 2$. When the left line of the tunnel was excavated to ZK41+123 ZK41+063, the surrounding rock conditions changed. According to the exposure of the tunnel face, it was mainly strongly weathered carbonaceous slate, with blastopelitic texture, layered and massive structure, extremely developed joint fissures, and the rock masses were broken and loose, with the attrition crushing surface accounting for more than $75 \%$. Fig. 1 shows the vault surrounding rock of Tunnel Face ZK41+088 of the left line.

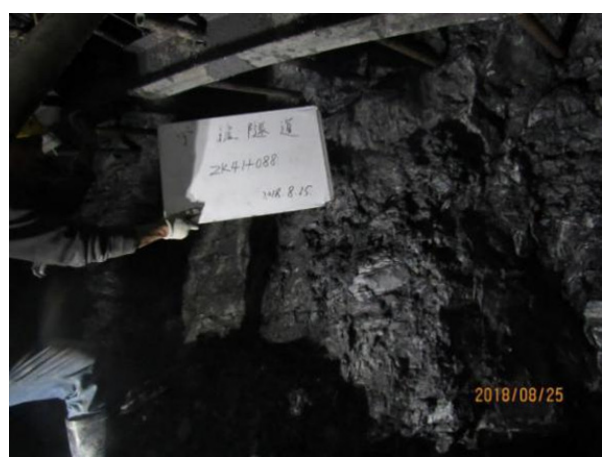

Fig. 1. Vault Surrounding Rock of Tunnel Face ZK41+088 of Left Line.

Table 1. Vertical Borehole Hydrofracturing Results.

\begin{tabular}{|c|c|c|c|c|c|c|c|c|}
\hline $\begin{array}{l}\text { Depth } \\
/ \mathrm{m}\end{array}$ & $\begin{array}{c}\begin{array}{c}\text { Fracture } \\
\text { pressure }\end{array} \\
P_{b}^{\prime} \\
/ \mathrm{MPa} \\
\end{array}$ & $\begin{array}{c}\text { Reopening } \\
\text { pressure } \\
P_{r}^{\prime} \\
/ \mathrm{MPa}\end{array}$ & $\begin{array}{c}\text { Closing } \\
\text { pressure } \\
P_{s}^{\prime} \\
/ \mathrm{MPa}\end{array}$ & $\begin{array}{c}\text { Head } \\
\text { pressure } \\
P_{H} \\
/ \mathrm{MPa}\end{array}$ & $\begin{array}{c}\text { Pore } \\
\text { pressure } \\
P_{0} \\
/ \mathrm{MPa}\end{array}$ & $\begin{array}{c}\text { Maximum } \\
\text { horizontal } \\
\text { principal } \\
\text { stress } \sigma_{H} \\
\quad / \mathrm{MPa} \\
\end{array}$ & $\begin{array}{c}\text { Minimum } \\
\text { horizontal } \\
\text { principal } \\
\text { stress } \sigma_{h} \\
\quad / \mathrm{MPa}\end{array}$ & $\begin{array}{c}\text { Direction of } \\
\text { maximum } \\
\text { horizontal } \\
\text { principal } \\
\text { stress }\end{array}$ \\
\hline 29.3 & 8.92 & 8.25 & 7.66 & 0.29 & 0.29 & 15.02 & 7.95 & \\
\hline 31.3 & 14.26 & 10.54 & 9.42 & 0.31 & 0.31 & 18.03 & 9.73 & \\
\hline 33.3 & 15.25 & 11.28 & 9.92 & 0.33 & 0.33 & 18.81 & 10.25 & $\mathrm{NW}^{\circ} 3^{\circ}$ \\
\hline 35.3 & 12.68 & 10.74 & 9.78 & 0.35 & 0.35 & 18.95 & 10.13 & \\
\hline 37.3 & 15.00 & 13.39 & 10.66 & 0.37 & 0.37 & 18.96 & 11.03 & NW65 \\
\hline 39.3 & 12.40 & 10.61 & 10.00 & 0.39 & 0.39 & 19.78 & 10.39 & \\
\hline
\end{tabular}

Table 2. Horizontal Borehole Hydrofracturing Results

\begin{tabular}{|c|c|c|c|c|c|c|}
\hline $\begin{array}{l}\text { Depth } \\
/ \mathrm{m}\end{array}$ & $\begin{array}{c}\text { Fracture } \\
\text { pressure } \\
P_{b}^{\prime} \\
/ \mathrm{MPa}\end{array}$ & $\begin{array}{c}\text { Reopening } \\
\text { pressure } \\
P_{r}^{\prime} \\
/ \mathrm{MPa}\end{array}$ & $\begin{array}{c}\begin{array}{c}\text { Closing } \\
\text { pressure }\end{array} \\
P_{s}^{\prime} \\
/ \mathrm{MPa}\end{array}$ & $\begin{array}{c}\text { Maximum } \\
\text { principal stress } \\
\sigma_{H} \\
/ \mathrm{MPa}\end{array}$ & $\begin{array}{c}\text { Minimum } \\
\text { principal stress } \\
\sigma_{h} \\
/ \mathrm{MPa}\end{array}$ & $\begin{array}{c}\text { Direction of } \\
\text { maximum } \\
\text { principal stress }\end{array}$ \\
\hline 33 & 16.15 & 11.58 & 9.14 & 15.84 & 9.14 & \\
\hline 35 & 17.81 & 12.63 & 9.06 & 14.55 & 9.06 & \\
\hline 37 & 21.90 & 17.52 & 11.39 & 16.65 & 11.39 & \\
\hline 39 & 24.28 & 19.05 & 12.01 & 16.98 & 12.01 & \\
\hline
\end{tabular}

\section{Support parameter optimization}

Combined with the geological conditions and aiming at the high ground stress characteristics of Ningchan Tunnel, the tunnel support parameters were optimized,
Table 1 and Table 2 are the vertical borehole hydrofracturing and horizontal borehole hydrofracturing results, respectively. By using the borehole hydrofracturing stress test method and rock uniaxial compression test, the obtained results at the tunnel site was that the average value of the maximum horizontal principal stress was $18.38 \mathrm{MPa}$, the average value of the minimum horizontal principal stress was $11.2 \mathrm{MPa}$ and the dominant direction of the maximum horizontal principal stress was $\mathrm{NW64}^{\circ}$. The average value of saturated compressive strength of rock, Rc, was $13.04 \mathrm{MPa}$, and the strength-stress ratio of rock, $\mathrm{RC} / \sigma \mathrm{max}$, was 0.71 , which was less than 4 . According to the Standard for Engineering Classification of Rock Mass (GB/T 50218-2014), it was an extremely high ground stress area. 
deformation", an experimental study for the optimization of support parameters were conducted on a total of four test sections.

S0 support was adopted in test section ZK41+120 ZK41+075, S1 support was adopted in test section ZK41+063 ZK41+033, S2 support was adopted in test section ZK41+033 ZK41+003 (See Fig. 2 for the parameters of S2 support), and S3 support was adopted in test section ZK41+003 ZK40+988. See Table 3 for specific design parameters.

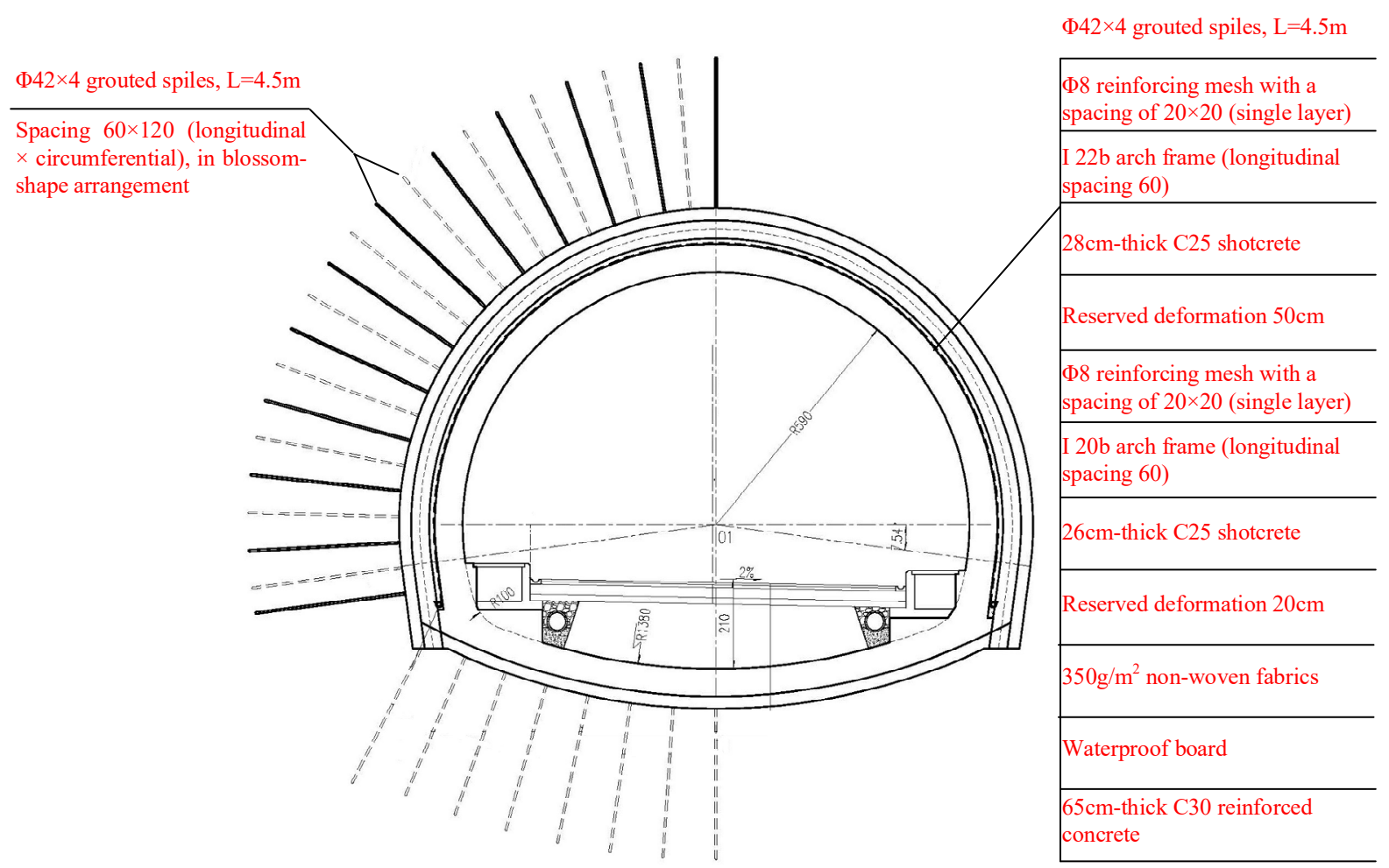

Fig. 2. S3 Support Parameters

Table 3. Support Parameter Design of Test Sections

\begin{tabular}{|c|c|}
\hline $\begin{array}{c}\text { Support } \\
\text { type }\end{array}$ & Support parameters \\
\hline S0 & $\begin{array}{l}\text { Forepoling: Adopt } \Phi 42 \times 4 \text { grouted spiles. } \mathrm{L}=4.5 \mathrm{~m} \text {, with a circumferential spacing of } 35 \mathrm{~cm} \text {, a longitudinal spacing of } \\
60 \mathrm{~cm} \text {, an setting angle of } 8 \sim 12^{\circ} \text { and an overlapping length of } 249 \mathrm{~cm} \\
\text { Primary support: } \Phi 8 \text { reinforcing mesh, I20b steel arch frame (layout spacing } 50 \mathrm{~cm}) \text {. Spray C } 25 \text { concrete with a } \\
\text { thickness of } 26 \mathrm{~cm} \text {. Use } 8 \text { groups of } \Phi 42 \times 4 \text { grouted spiles }(\mathrm{L}=5 \mathrm{~m}) \text { in the feet-lock bolts of each arch frame }(2 \mathrm{in} \\
\text { each group) } \\
\text { Secondary lining: Adopt } 50 \mathrm{~cm} \text {-thick } \mathrm{C} 40 \text { reinforced concrete }\end{array}$ \\
\hline S1 & $\begin{array}{l}\text { Forepoling: } \Phi 42 \text { grouted spiles, } \mathrm{L}=4.5 \mathrm{~m} \text {. } \\
\text { System anchor bolt: } \Phi 42 \text { grouted spiles, } \mathrm{L}=4.5 \mathrm{~m} \text {. } \\
\text { Outer primary support: } \Phi 8 \text { reinforcing mesh, I22b arch frame (layout spacing } 60 \mathrm{~cm} \text { ). Spray } 28 \mathrm{~cm} \text {-thick } \mathrm{C} 25 \\
\text { concrete } \\
\text { Reserved deformation: } 30 \mathrm{~cm} \\
\text { Inner primary support: } \Phi 8 \text { reinforcing mesh, } \mathrm{I} 18 \text { arch frame (layout spacing } 60 \mathrm{~cm} \text { ). Spray } 28 \mathrm{~cm} \text {-thick C25 concrete } \\
\text { Reserved deformation: } 25 \mathrm{~cm} \\
\text { Secondary lining: } 65 \mathrm{~cm} \text {-thick C } 30 \text { reinforced concrete }\end{array}$ \\
\hline S2 & $\begin{array}{l}\text { Forepoling: } \Phi 42 \text { grouted spiles, } \mathrm{L}=4.5 \mathrm{~m} \text {. } \\
\text { System anchor bolt: } \Phi 42 \text { grouted spiles, } \mathrm{L}=4.5 \mathrm{~m} \text {. } \\
\text { Outer primary support: } \Phi 8 \text { reinforcing mesh, } \mathrm{I} 22 \mathrm{~b} \text { arch frame (layout spacing } 60 \mathrm{~cm} \text { ). Spray } 28 \mathrm{~cm} \text {-thick } \mathrm{C} 25 \\
\text { concrete } \\
\text { Reserved deformation: } 30 \mathrm{~cm} \\
\text { Inner primary support: } \Phi 8 \text { reinforcing mesh, } \mathrm{I} 20 \text { arch frame (layout spacing } 60 \mathrm{~cm} \text { ). Spray } 28 \mathrm{~cm} \text {-thick C25 concrete } \\
\text { Reserved deformation: } 25 \mathrm{~cm} \\
\text { Secondary lining: } 65 \mathrm{~cm} \text {-thick C } 30 \text { reinforced concrete }\end{array}$ \\
\hline
\end{tabular}




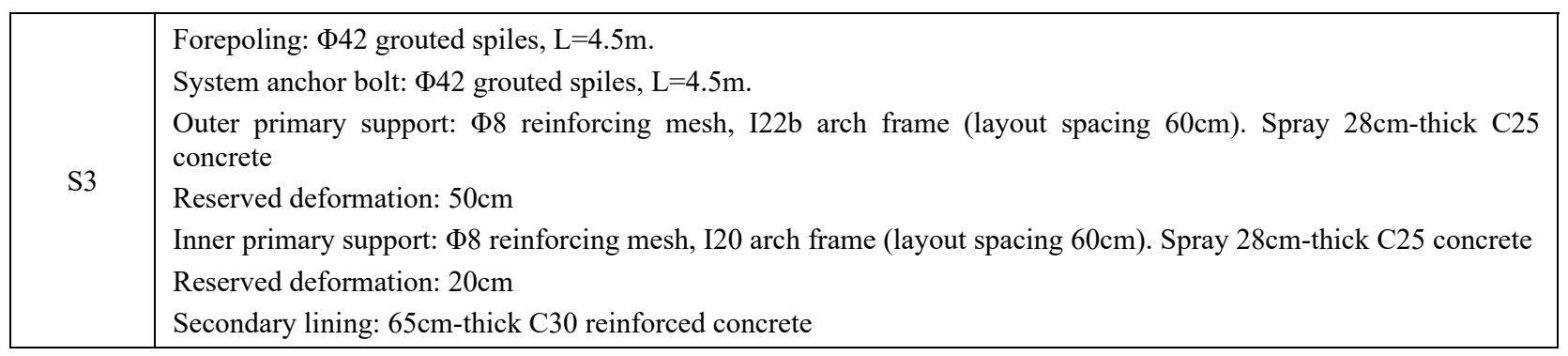

\section{Layout of monitoring points in test sections}

\subsection{Monitoring contents in the tests}

In order to master the deformation development of Ningchan high ground stress tunnel after excavation and evaluate the advantages and disadvantages of the existing support schemes in time, the field monitoring mainly covered the following two aspects:
(1) Vault settlement value monitoring;

(2) Sidewall convergence value monitoring.

\subsection{Layout of monitoring points in test sections}

In order to measure the development law of vault settlement and horizontal convergence after tunnel excavation, a total of five monitoring points were arranged on vault, left spandrel, right spandrel and left sidewall. The detailed layout is shown in Fig. 2.

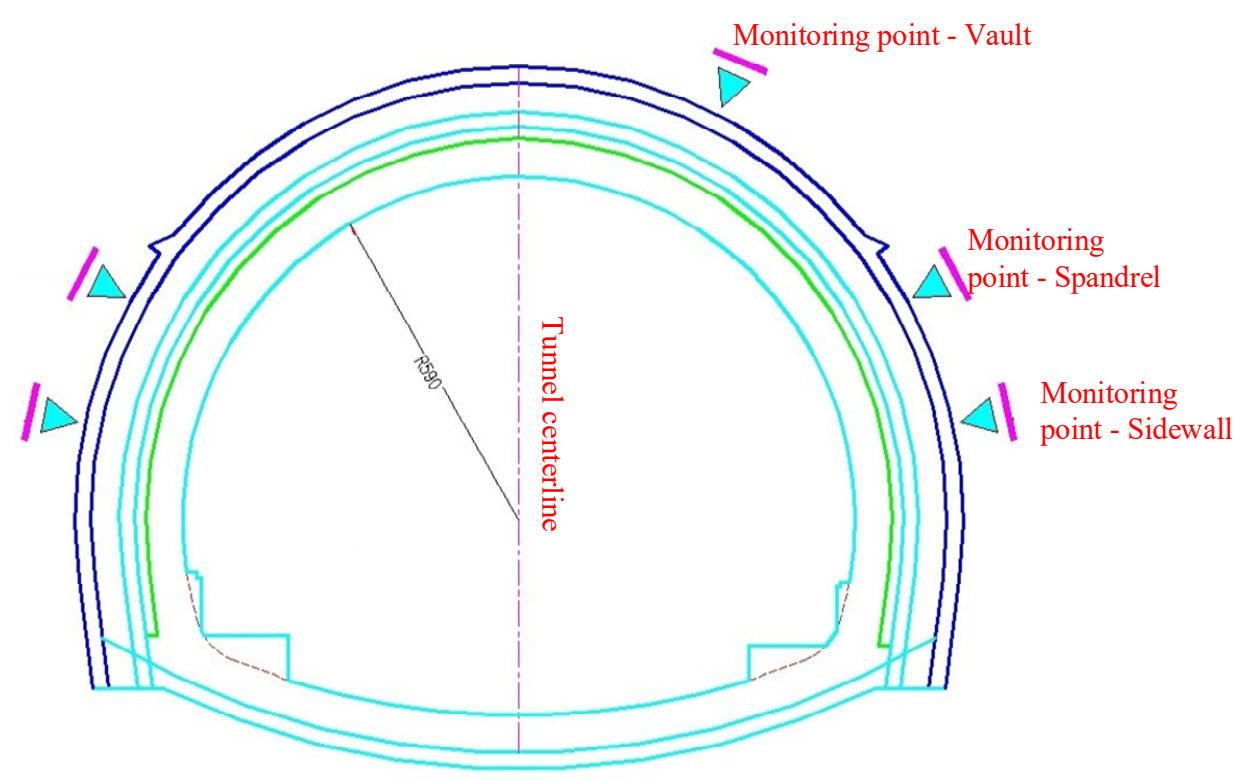

Fig. 3. Layout of Monitoring Points

\subsection{Analysis of test results}

\section{Analysis on effect of S0 support}

The primary support structure with $\mathrm{I} 20 \mathrm{~b}$ as the main skeleton adopted in the original design scheme has poor effect. According to the monitoring data of Section ZK41+120 ZK41+075 in the left line, the vault settlement and horizontal convergence values were large after the completion of the primary support, and there was no sign of tending towards stability. The maximum vault settlement reached $6 \mathrm{~cm} / \mathrm{d}$, and the maximum horizontal convergence reached $11 \mathrm{~cm} / \mathrm{d}$. Under the action of high ground stress, the primary support structure could no longer resist the surrounding rock pressure, and some sections even had serious arch frame deformation (as shown in Fig. 4) and shotcrete spalling (as shown in Fig. 5).

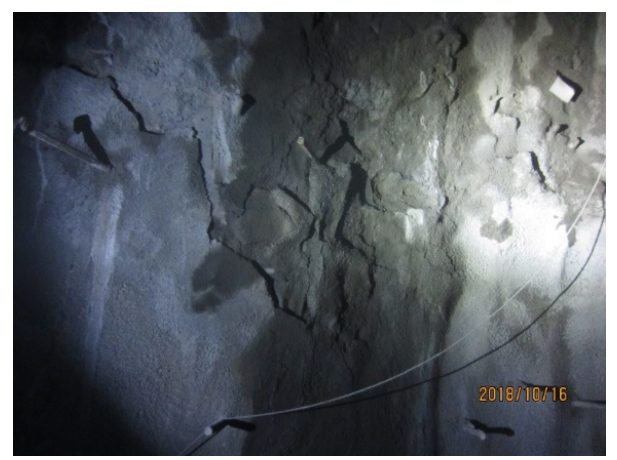

Fig. 4 Severe Arch Frame Deformation 


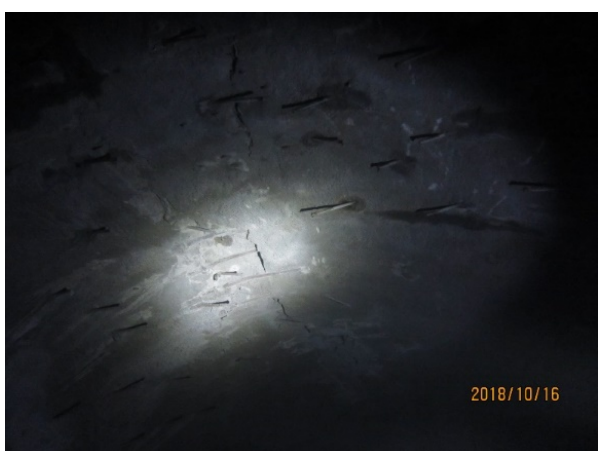

Fig. 5 Spalling of Sprayed Concrete

In order to prevent the further development of deformation and ensure the safety of the primary support of the tunnel, radial grouting reinforcement with I18 steel arch reinforcement and $\Phi 42$ spile was conducted for the primary support of this section. After the completion of the "double-layer primary support" construction, although the accumulative deformation is large, the rate of vault settlement and horizontal convergence of surrounding rock was controlled to a certain extent, and the vault settlement and convergence tended to be stabilized. That is to say, the "double-layer primary support" had a certain control effect on large deformation of high ground stress tunnel. On this basis, "double-layer primary support" was determined as the main support measure in the next stage, and double-layer primary support test was carried out in Section ZK41+063 ZK40+988 of the left line to optimize the support parameters.

2. Analysis on effect of S1 support

About 55 days after S1 support was adopted in Section ZK41+063 ZK41+033 (See Fig. 6 for the result after the construction of the inner primary support), the arch settlement and horizontal convergence tended to be stabilized, the arch frame and shotcrete were intact, and there was no steel frame damage or concrete falling off. Compared with single-layer primary support, doublelayer primary support can obviously control large deformation in high ground stress. The final value of horizontal convergence was between $208 \mathrm{~mm}$ and $338 \mathrm{~mm}$, but the final value of arch settlement was between $478 \mathrm{~mm}$ and $704 \mathrm{~mm}$, which had exceeded the reserved deformation, so the support parameters need to be further optimized.

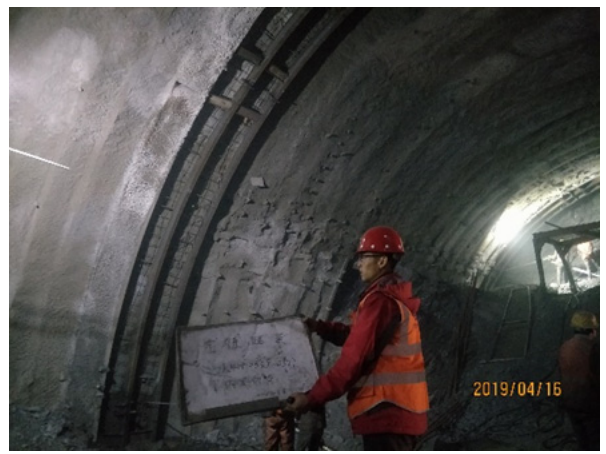

Fig. 6. Inner Primary Support of S1 Support Completed
Fig. 7 is the convergence duration curve of Section ZK41+038 when adopting S1 double-layer primary support. The figure shows: (1) Compared with the settlement values of vault and right spandrel, the settlement value of left spandrel was relatively larger, that is, the location of the maximum settlement value was basically consistent with the direction of the maximum principal stress $\left(\mathrm{NW64^{ \circ }}\right)$; (2) The arch settlement can be divided into three stages: the rapid development stage before the completion of the inner primary support, with a settlement accounting for $61 \%$; the slow-down stage from the completion of the inner primary support to the full face closure, with a settlement accounting for $31 \%$; the slow deformation stage after the full face closure, with a settlement accounting for $8 \%$. That is, after the inner support was constructed, the arch settlement was still very large, and the settlement was close to $40 \%$. In the next optimization, the stiffness of the inner primary support can be appropriately increased.

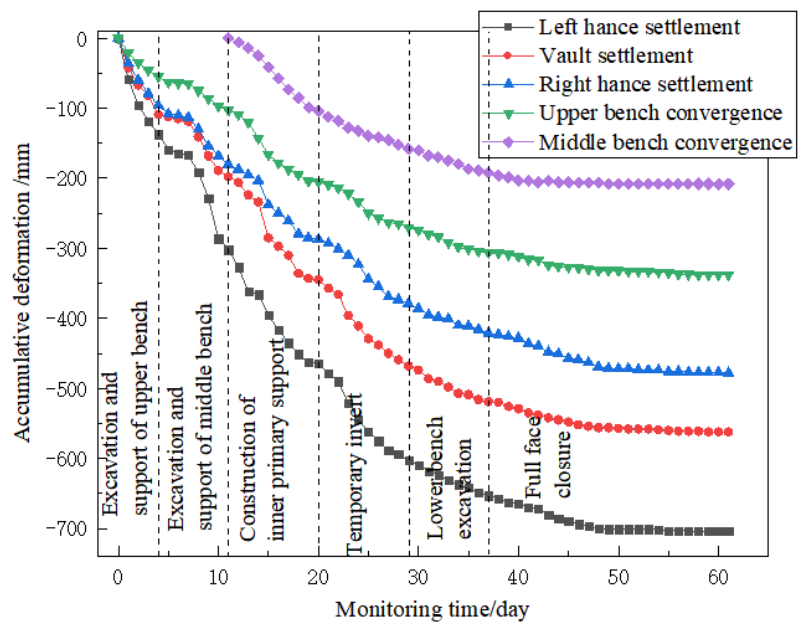

Fig. 7 Convergence Duration Curve of Section ZK41+038

\section{Analysis on effect of S2 lining support}

On the basis of S1 support, this section mainly improved the stiffness of inner primary support, and adjusted the arch frame from I18 to I20b. After S2 support was adopted in Section ZK41+033 ZK41+003, the arch settlement and horizontal convergence tended to be stabilized in about 55 days. The final value of arch settlement was between $443 \mathrm{~mm}$ and $622 \mathrm{~mm}$, which was reduced by $7 \% \sim 12 \%$. The final value of peripheral convergence was between $187 \mathrm{~mm}$ and $359 \mathrm{~mm}$, and the lower bench convergence value decreased, but the upper bench convergence increased. Obviously, the maximum deformation (the settlement value of the left hance was $622 \mathrm{~mm}$ ) had exceeded the reserved deformation of $55 \mathrm{~cm}$. Although increasing the stiffness of the inner primary support brought some reduction in the cumulative deformation, the supporting effect was still poor.

Fig. 8 is the convergence duration curve of Section ZK41+006. It can be seen that after the inner primary support was completed, the arch structure with higher stiffness could not control the deformation completely, and the surrounding rock pressure at this time was still very high, and its release took a long time. Although adopting the optimization measure of "stiff resisting" can 
reduce the accumulative settlement to a certain extent, it still cannot achieve the expected supporting effect.

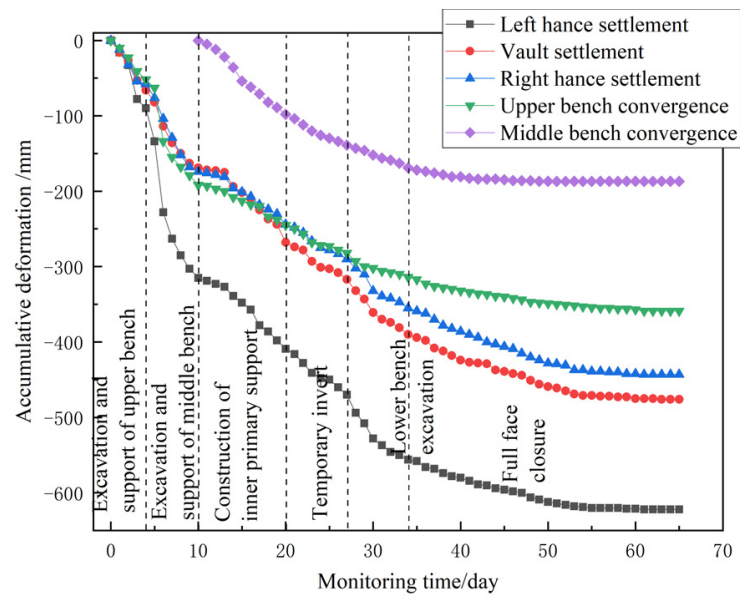

Fig. 8 Convergence Duration Curve of Section ZK41+006

\section{Analysis on effect of S3 lining support}

On the basis of S2 support, this section mainly increased the reserved deformation: the total reserved deformation was adjusted to $70 \mathrm{~cm}$, and the reserved deformation of the inner and outer primary supports was adjusted from $30 \mathrm{~cm}$ to $50 \mathrm{~cm}$. The increased reserved deformation of S3 support was shown in Fig. 9. After S3 support was adopted in Section ZK41+003 ZK40+988, the supporting effect was good: the arch settlement and horizontal convergence had tended to be stabilized in about 40 days, the final value of arch settlement was between $411 \mathrm{~mm}$ and $525 \mathrm{~mm}$, and the final value of horizontal convergence was between $73 \mathrm{~mm}$ and $214 \mathrm{~mm}$, both of which were less than the reserved deformation of $70 \mathrm{~cm}$.

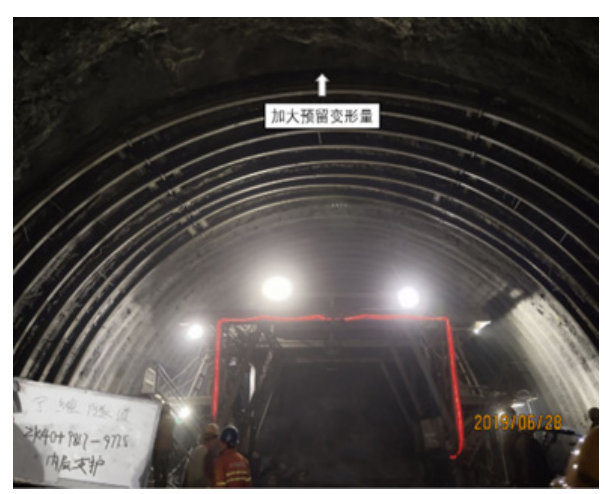

Fig. 9 Increasing Reserved Deformation of S3 Support

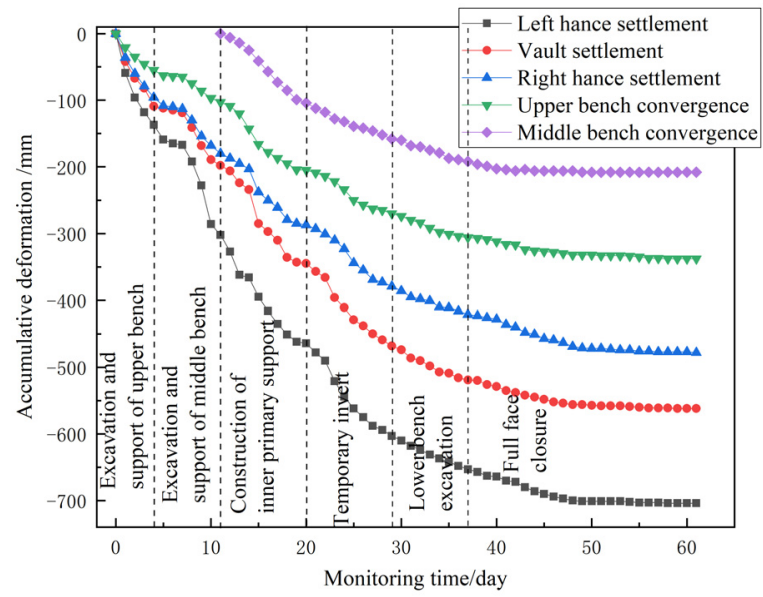

Fig. 10. Convergence Duration Curve of Section ZK40+991

Fig. 10 is the convergence duration curve of Section ZK40+991. Due to the enough deformation set between the inner and outer primary supports, the surrounding rock pressure was released enough. After the inner support was completed, the settlement of S3 support was relatively small, and it tended to converge in a short time

5. Comparative Analysis of Supporting Effects

Table 4. Comparison of Supporting Effects

\begin{tabular}{|c|c|c|c|c|c|}
\hline $\begin{array}{c}\text { Support } \\
\text { type }\end{array}$ & $\begin{array}{c}\text { Optimization } \\
\text { measures }\end{array}$ & $\begin{array}{c}\text { Maximum } \\
\text { accumulative } \\
\text { settlement value }\end{array}$ & $\begin{array}{c}\text { Maximum cumulative } \\
\text { convergence value }\end{array}$ & $\begin{array}{c}\text { Reserved deformation } \\
\text { of inner and outer } \\
\text { layers }\end{array}$ & $\begin{array}{c}\text { Convergence } \\
\text { time }\end{array}$ \\
\hline S0 & $\begin{array}{c}\text { Single-layer } \\
\text { primary support }\end{array}$ & - & - & - & $\begin{array}{c}\text { No } \\
\text { convergence }\end{array}$ \\
\hline S1 & $\begin{array}{c}\text { Double-layer } \\
\text { primary support }\end{array}$ & $704 \mathrm{~mm}$ & $338 \mathrm{~mm}$ & $\begin{array}{c}\text { About } 55 \\
\text { days }\end{array}$ \\
\hline S2 & $\begin{array}{c}\text { Increasing the } \\
\text { stiffness }\end{array}$ & $622 \mathrm{~mm}$ & $359 \mathrm{~mm}$ & $30 \mathrm{~cm}$ & $\begin{array}{c}\text { About } 55 \\
\text { days }\end{array}$ \\
\hline S3 & $\begin{array}{c}\text { Increasing the } \\
\text { reserved } \\
\text { deformation }\end{array}$ & $525 \mathrm{~mm}$ & $214 \mathrm{~mm}$ & $50 \mathrm{~cm}$ & $\begin{array}{c}\text { About } 40 \\
\text { days }\end{array}$ \\
\hline
\end{tabular}

The original design scheme adopted single-layer primary support, which could not effectively control large deformation. After adopting S1 double-layer primary support, although the large deformation was controlled, the accumulative deformation still exceeded the reserved deformation, and its deformation convergence period was long. The deformation could be reduced to a certain extent by adopting the inner primary support with higher stiffness, but because the reserved deformation between the inner and outer supports was small, the surrounding rock pressure could not be released before the construction of the inner support, resulting in the subsequent accumulative deformation still exceeding the reserved deformation, and the convergence period was still very long. Setting reserved deformation between the inner and outer primary 
supports could make the surrounding rock pressure released, and the accumulative deformation was small and the convergence period was short.

\section{Conclusions}

Through the optimization study on the support parameters in the test sections of Ningchan high ground stress tunnel, the following conclusions are obtained after comprehensive analysis:

(1) The single-layer supporting structure with I20b as the main skeleton cannot cope with the high ground stress of Ningchan Tunnel, which is mainly manifested by arch deformation, shotcrete spalling and excessive and non-convergent accumulative deformation;

(2) Double-layer primary support can effectively deal with the non-convergent deformation problem of Ningchan high ground stress tunnel. After adopting double-layer primary support, the maximum deformation position of Ningchan Tunnel is consistent with the direction of the maximum ground stress, and its deformation development presents three stages: the rapid development stage before the completion of the inner primary support, the slow-down stage from the completion of the inner primary support to the full face closure, and the gradual stabilization stage after the full face closure;

(3) Increasing the stiffness of inner primary support can reduce the deformation to a certain extent, but properly increasing the reserved deformation of inner and outer primary support and giving the surrounding rock pressure an appropriate release time will produce better supporting effect, which is manifested in the reduction of accumulative deformation and shortening of convergence period.

\section{Acknowledgments}

This work is jointly supported by the Science and Technology Project of Transportation Department of Qinghai Province (No. 2020-01).

\section{References}

1. Chen Jun quan. The treatment of large deformation of soft surrounding rock in highway tunnel [J]. Highway Traffic Technology, 2018, 34(05):106-112.

2. Technology - Materials Research; Studies from Swinburne University of Technology Provide New Data on Materials Research (Large Deformation of Corrugated Sandwich Panels Under Three-point Bending)[J]. Journal of Technology,2020.

3. Wang Wan ping, Li Jian fei, Xin jiang he, Bie Su ping. Analysis of Large Deformation Structure of Large Span Flat Extreme Soft Rock Tunnel [J]. Highway Traffic Technology,2018,34(S1):45-51.

4. Cheng Xi. Application of Monitoring and Measurement in Treatment of Large Deformation of Jiangluling Tunnel [J]. Highway Traffic Technology, 2016,32(06):115-120.
5. Yin Liu,Brian Moran. Large deformation near a crack tip in a fiber-reinforced neo-Hookean sheet[J]. Journal of the Mechanics and Physics of Solids, 2020,143 .

6. Ummer Amin Sheikh,Azher Jameel. Elasto-plastic large deformation analysis of bi-material components by FEM $[\mathrm{J}]$. Materials Today: Proceedings, 2020,26(Pt 2).

7. Cao Xiao ping, Wei Fei peng, Wang Bo, Liu Zi yang. Experimental study on reasonable support scheme of soft rock tunnel with high in-situ stress [J]. Journal of Railway Engineering, 2018, 35(07): $65-71+102$.

8. Wang Dao yuan, Liu jia, Zhang Chuo etc. High insitu stress fractured buried tunnel with large deformation control method for field test study [J]. Chinese Journal of Geotechnical Engineering: 1-10.

9. Wang Bo, Guo Xin xin, He Chuan, Wu De xing. Analysis on Characteristics and Development Trend of High-in-situ Stress Tunnel Support Technology in China [J]. Modern Tunneling Technology, 2018, 55(05): 1-10.

10. Cui Guang yao, Wang Xue lai, Wang Ming sheng. Field test study on large deformation control in fracture zone of deep buried tunnel with high in-situ stress [J]. Chinese Journal of Geotechnical Engineering, 2019, 41(07): 1354-1360.

11. Li Guo liang, Zhu Yong quan. Large deformation control technology of weak surrounding rock with high in-situ stress in Wushaoling tunnel [J]. Journal of Railway Engineering, 2008(03): 54-59.

12. Li Yan zong, Zhao Shuang. Construction Scheme and Deformation Analysis of Multi-layer Support Structure for a High In-situ Stress Soft Rock Tunnel [J]. Modern Tunneling Technology, 2019, 56(03): 161-165.

13. Liu Zhao wei, Wang Ming sheng, Fang Jun bo. Experimental study on supporting system of tunnel with high in-situ stress and large deformation [J]. Chinese Journal of Civil Engineering, 2010, 43(05): 111-116.

14. Liu Gao, Zhang Fei yu, Li Xin zhao et al. Analysis of Large Deformation Characteristics and Mechanism of Muzhailing Tunnel [J]. Chinese Journal of Rock Mechanics and Engineering, 2005(S2): 5521-5526.

15. Zheng Xi xi, Wu Sheng zhong. Study on Ground Deformation Control of Large Span Shallow Buried Asymmetric Urban Tunnel with Small Clear Distance [J]. Highway Traffic Technology, 2019, 35(03):94-99.. 